\title{
Authorities Dealing with REACH
}

\author{
Christiane Heiß ${ }^{\star}$, Caroline Hoffmann, Christoph Schulte, Lars Tietjen, and Ulrike Frank
}

\begin{abstract}
REACH establishes a new principle for assessing the risks of chemicals towards humans and the environment: producers and importers of substances bear the main weight of the new substance stewardship. They have to register the substances which are produced or imported with the central EU Chemicals Agency. This includes consideration of uses and possible releases of the chemical throughout the product chain. In addition, producers and importers of chemicals have to ensure that management measures are adequate to control the associated risks over the life-cycle of the chemical. By introducing the 'no data - no market' principle REACH intends to build a dynamic system of growing risk knowledge and risk control for chemicals. In turn, authorities will withdraw from compiling detailed risk assessments and risk reduction strategies. Local, reversible risks and point emission sources will no longer be a topic of expert committees at EU level. During the registration procedure authorities might serve as helpers e.g. by establishing help-desks to support the compilation of the registration dossiers. For the evaluation step of REACH authorities will be able to concentrate on substances and uses of high concern which pose a risk to humans and the environment. Where risks are identified as not adequately controlled and therefore needing regulation at Community level, authorities will propose the respective substances as candidates for authorisation. In addition authorities might suggest restrictions for certain uses. For these legal elements the responsibility still lies with the authorities. Chemicals with persistent, bioaccumulative and toxic properties (PBT-substances) are considered as substances of very high concern and therefore should be subject to authorisation. Producers and importers are required to identify potential PBT-substances in the registration dossiers. Since the responsibility for introducing legal measures remains with the authorities, they also need to implement mechanisms to identify potential candidates during the evaluation procedure.
\end{abstract}

Keywords: Authorities - Chemical safety report · PBT assessment $\cdot$ REACH $\cdot$ Risk assessment

This article is based on the Common Position [1][2] adopted by the Council on 27.06.2006.

\section{Introduction}

REACH establishes a new quality of substance stewardship. In doing so REACH brings about the paradigm shift [3] which was called for in chapter 19 of the UN Agenda 21 on sustainable development. This demands environmentally sound management of to-

${ }^{\star}$ Correspondence: C. Heiß

Umweltbundesamt Dessau

Assessment of New and Existing Substances (IV1.5)

Wörlitzer Platz 1

D-06844 Dessau

Tel.: +49340 21033159

Fax: +4934021043159

E-Mail: Christiane.Heiss@uba.de xic chemicals [4]. With REACH, this task is with the chemical industry that becomes responsible for the safe production, marketing and use of chemical substances during their whole life cycle in future. As is the case with almost all other products already, producers and importers of chemicals must now prove that their products are safe before they get onto the market. Claiming 'no data-no market' for new and existing chemicals REACH intends to build up a dynamic system of growing risk knowledge and risk control.

This will free authorities from the resource-intensive demands placed on them under the Existing Substances legislation. In future, authorities will be able to focus their resources on those substances and uses of high concern which pose a risk to humans and the environment and therefore require regulation at Community level. Most procedural and methodical standards that were developed over the last decade to assess new and existing chemicals will be maintained, but the roles of authorities and industry in the decision making process and in risk management will change fundamentally.

The scientific quality of risk assessment will depend much on the information exchange along the product chain. However, it can be assumed that quality and accuracy of information will depend on the economic interests and market position of the actors. While downstream users might prefer a detailed disclosure of dangerous substances in preparations, manufacturers and formulators intend to keep their recipes confidential to protect their economic interests. Authorities will have to deal with new uncertainties of risk information and need to develop a strategy of controlling the outcome of REACH that frames the substance stewardship of industry adequately.

\section{Shifting Roles - Shifting Responsibilities}

In the current EU's risk assessment procedures for industrial chemicals and preparations [5-7] the Authorities of the EU Member States are responsible for assessing a chemical's risk to humans and the environment. Priority lists and Guidance Documents [8] were developed at EU level to harmonize decision-making of authorities. The role of the producing companies was to submit substance information and participate in the risk assessment procedure as experts and stake- 
holders. The cooperation process was based on a simple incentive for producers: If the data indicated a risk, they had the opportunity to modify the assessment by providing additional information, e.g. test data or refined exposure data [9].

In more than ten years, the risk assessment procedure for existing substances came to a result for about 70 out of 141 priority substances. For about 35 substances legal measures were recommended by the EU Commission. This iterative procedure was exceedingly time consuming for existing substances, but more successful for new chemicals which were assessed before marketing. However, in future approximately 30,000 existing substances need to be assessed after having been on the market without any form of risk assessment, or have to be withdrawn from market and use.

Under REACH, new and existing substances will be treated equally. This will put an end to the intrinsic advantages which the use of existing chemicals incorporated. Now instead the incentive will be on the development of sustainable products and on creating innovative processes.

In future, producers and importers of substances, i.e. those who place these substances on the market, will bear the main weight of the new substance stewardship. Having considered all data available to assess potential risks, information is passed on to their customers. Users of substances bear 'second responsibility' by informing their supplier about uses, checking the producer's

\section{The Three Basic Instruments of REACH}

Registration: $\mathrm{REACH}$ obliges industry to register existing substances and their uses in a central database at the EU Chemicals Agency. 'No data, no market' aims at generating basic knowledge about all substances which are produced or put on the market with more than 1 t/a and actor. Data required depends on volume of marketing and dangerous substance properties. The scope of risk assessment integrates downstream uses and the whole life cycle of a substance.

Evaluation: Authorities will evaluate industry's chemical safety reports and restrict uses of substances which can not be adequately controlled.

Authorisation: Every use of a substance with very high concern needs a specific authorisation from the EU Commission. Those are substances with carcinogenic, mutagenic or reprotoxic (CMR) properties, and those which are persistent, bioaccumulative and toxic (PBT) or very persistent and very bioaccumulative (vPvB). recommendations for a safe use and adapting technical processes or product design, if necessary. According to REACH, every economic actor has to ensure that his management measures constitute an adequate control of substances and processes.

Substance stewardship means that producers and downstream users gain more freedom of choice and more flexibility in managing risks. But this new freedom is based on challenging decisions: Every producer has to revise his substance portfolio and weigh risk potentials against economic benefits. Every downstream user has to weigh up the need for information necessary for the producer to decide the appropriate management strategy against the economic risk in communicating information on processes and use conditions with his supplier. Safety and economic success will depend very much on individual use conditions and a proactive attitude towards sustainable product design.

In turn, authorities withdraw from compiling detailed risk assessments and risk reduction strategies for every substance regardless of the relevance of the risks. Authorities no longer need to search for the complete set of uses and identify all possible emission sources. In addition, local, reversible risks and point emission sources will no longer be a topic of expert committees at EU level. Authorities can focus their resources on the evaluation of chemical safety reports for substances of high concern and on entering those substances which give rise to very high concern into the authorisation procedure. The EU Commission continues to recommend restrictions on marketing and use. In addition, resources might become available to develop and refine guidance and optimise assessment strategies addressed at emerging risks.

As a new task, authorities need to develop new support and advice options (such as help desks) and an information management system which improves horizontal information exchange and risk communication between authorities as well. Member States, EU Commission and the new EU Chemicals Agency in Helsinki share the work load and tasks.

\section{Communication Up and Down the Supply Chain}

\subsection{REACH Relies on Information}

The new approach to managing risks relies on risk communication and risk competence distributed all along the supply chain. The key tools will be the safety data sheet (SDS, see Section 4.1.) and the technical dossier (Section 4.2.), including a chemical safety report (CSR) for certain substances. The REACH system will combine the scattered knowledge on uses which the producer shall integrate into the exposure estimation of their risk assessment. Producers may discard uses which are difficult to manage or substances which provide 'low value but high risk'.

The system is supported by the new REACH IT infrastructure at the Chemicals Agency of the EU. It will consist of two main systems: Part one is the international uniform chemical information data base (IUCLID 5). For producers and importers, IUCLID 5 will be the tool for submitting dossiers. For authorities it will be the central data repository and tool for evaluation, restriction, and authorisation proposals. The second part of the infrastructure will be REACH-IT: this will be the support for managing the complete system and consist of the Agency web portal, a workflow system, and a tool for dissemination [10].

\subsection{How Much Guidance Does Substance Stewardship Need?}

During the political discussion on REACH various objections were presented concerning the workability of the system. The EU Commission, Parliament [11] and Council [1] reacted to these concerns with many concessions. Additionally the REACH Implementation Projects (RIP) [12] will provide stakeholders with the opportunity to participate and map out the main tasks in detail. Within the projects, guidance for all participants is developed to define the change of responsibilities and the upcoming tasks in detail. The main challenges of the RIPs are to develop simple, practicable standards for assessment and to implement the intended flexibility for 'substance and use tailored' decisions.

Having learned the lessons from existing substance assessment, guidance is developed integrating the recent knowledge on the use of structure-activity relationships, experiences from the assessment of similar substances ('read across') and grouping of substances and uses. This methodic multitude meets the economic interests of producers and importers. A more difficult task is how to meet the guidance needs of small and medium enterprises. They require short and specific advice, which means a large variety of cases has to be developed.

\subsection{Motivation Will Matter}

The workability of the REACH system will not only depend on official guidance and expert knowledge of economic actors. The intended self responsibility needs motivation and a proactive attitude. Some dominant distributors or industrial producers of consumer goods (e.g. the car industry) drive their suppliers towards extensive risk and substance information already. Actors who visibly comply with REACH could have a market advantage. But these economic incentives might not work in general as presently the investment in safer products and 
processes is often little rewarded in business to business markets where almost $50 \%$ of the downstream users are trading.

Therefore the dominant impulse to motivation has to be legal: The strong principle of 'No data no market' urges every stakeholder to fulfil registration provisions. Sanctions for non-compliance will be defined by the Member States.

Legal benefits and exemptions which are based on the new quality of risk competence would be strong incentives for a REACH compliant risk management. Vice versa REACH will strengthen the legal status of substance stewardship and could initiate a streamlining process of legal duties aiming at environment protection from different points of view (Fig. 1).

\subsection{Advice, Audit and Information Management by Authorities}

To fulfil their new role authorities have to accompany every step of REACH by suitable institutions and incentives. Article 123 provides that Member States shall

- establish national help desks to support and advice SME;

- establish a mechanism of horizontal communication between authorities to make better use of the REACH information.

In addition, the national authorities have to inform the public about the risks arising from substances where this is considered necessary for the protection of human health or the environment. The Chemicals Agency will ensure that substance information is publicly available via the Internet.

As further challenging tasks, a system to ensure quality of information in the SDS needs to be implemented, and a targeted monitoring strategy that reflects the practical outcomes and effects in the environment has to be developed.

\section{Registration - Authorities as Helpers during Assessment}

Substances intended to be marketed continuously need to be registered within defined timeframes by producers and importers. This procedure guarantees that basic knowledge on properties and uses is available for every substance that exceeds the $1 \mathrm{t} / \mathrm{a}$ marketing volume. In general, the amount and quality of information refer to the production volume by using the procedural concept developed as Technical Guidance Document TGD [8]. The crucial new element is the exchange of use and substance data up and down the supply chains (Fig. 2).

Authorities will not be involved in the registration process directly. The economic actors in every supply chain have to identify their roles and tasks under REACH and organise the risk communication process by

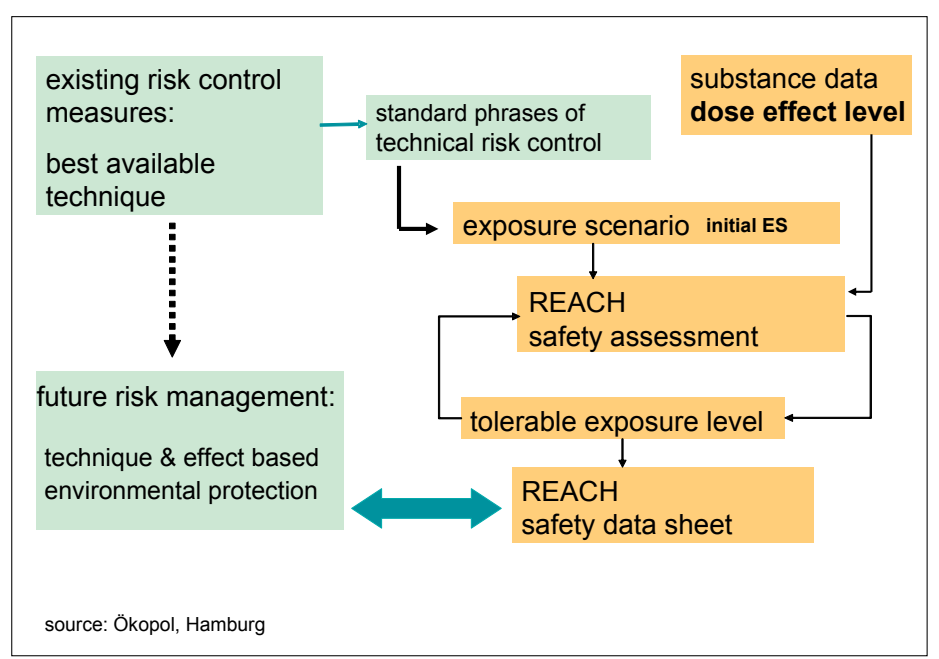

Fig. 1. Links between REACH and technical risk control measures

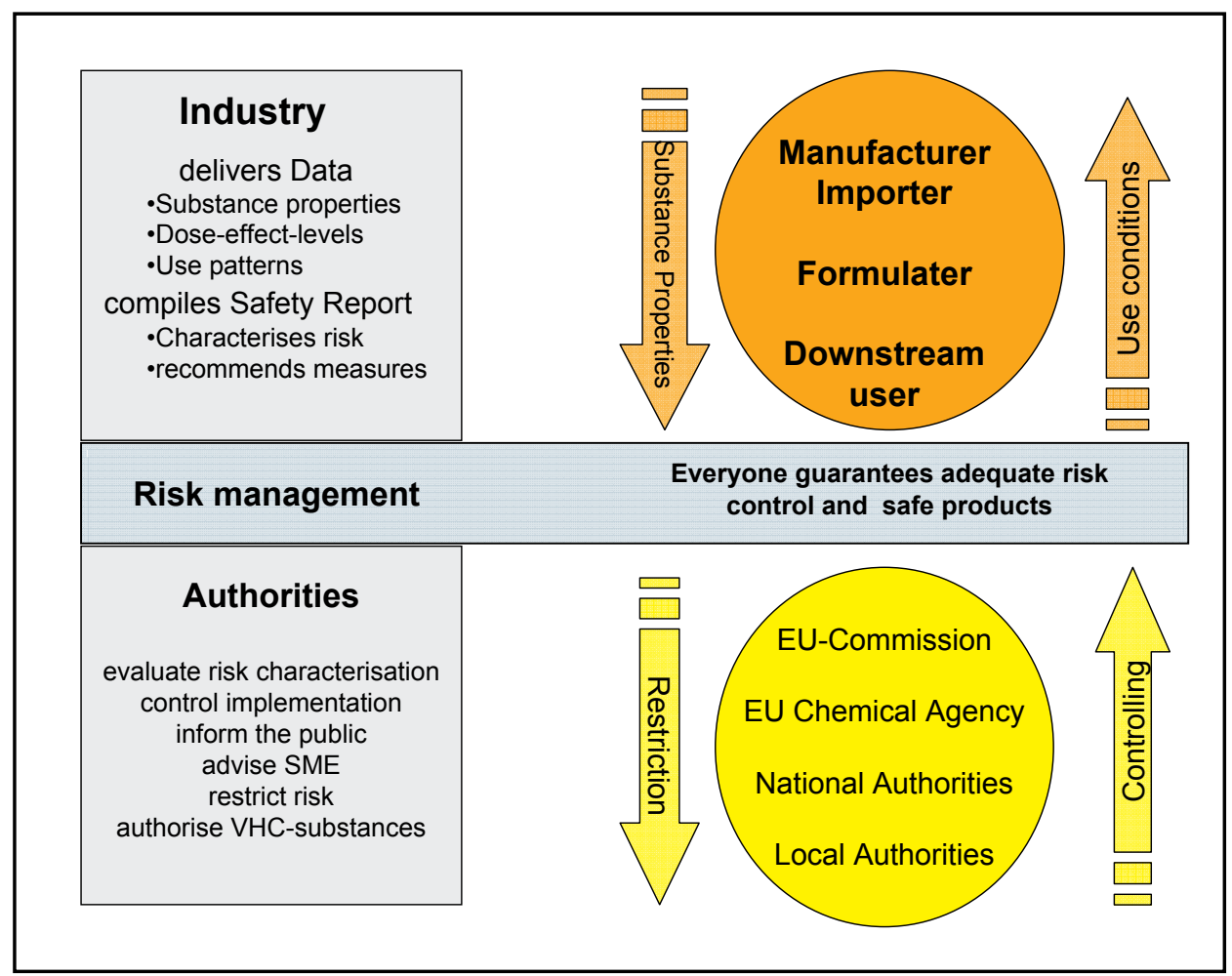

Fig. 2. Scheme of new roles and tasks

themselves. Authorities backup the registration indirectly: Small and medium enterprises may get support from national help-desks, but in principle economic actors are responsible for the quality of the registration dossier. Authorities can concentrate on research and development of methodical approaches to make the risk assessment more efficient. In particular they support the development of 'intelligent testing methods' to replace animal testing. As stakeholders they participate in the REACH preparations, implementation and develop technical and procedural guidance.

Registration depends on trust in the agreement to shift responsibilities. Registration data are checked electronically for completeness only. As a highly standardised procedure, this is neither a check for the correctness nor for the quality of the dossier: the responsibility for the quality of the data remains firmly with industry. Considering that in total only $5-10 \%$ of the registration dossiers might be evaluated by the authorities, the probability of missing a registration which is formally complete but of low reliability is high. From the German authorities' point of view the reliability of data should be strengthened by a mandatory peer review process or quality management system [13].

\subsection{Safety Data Sheet}

The main instrument to communicate risk $(\mathrm{R})$ and safety $(\mathrm{S})$ phrases, risk thresholds and risk management measures are 
safety data sheets (SDS). They are passed on down the supply chain and contain the use specific information that was gathered by the producer during the preparation of the registration dossier. Authorities will neither comment data nor recommendations for a safe use in the SDS.

The quality of safety data sheets for preparations was evaluated by the Chemical Legislation European Enforcement Network( CLEEN) [14]. In this project 491 SDS were evaluated by Germany with the result as shown in Table 1.

\subsection{Technical Dossier and Chemical Safety Report}

A technical dossier must be submitted if the marketing volume of a substance exceeds one tonne per producer or importer per year. It contains basic information on the properties, uses and the classification of the substance. In addition, guidance on safe use of the chemical is proposed.

For each chemical exceeding the 10 t/a production or importing level the registrant must submit a chemical safety report (CSR). The CSR can be compared to a risk assessment report in the current EU Existing Substances regulation amended by the recommendations for a safe use. The CSR communicates how chemical risks can be

\section{Table 1. Deficits of SDS}

Severe deficits: $23.3 \%$

(Deficiencies that are also reported to the police. This is the case if the toxic symbol and/or the corresponding $\mathrm{R}$ and $\mathrm{S}$ phrases are missing)

Mayor deficits: $17.2 \% \quad$ (Other R/S phrases missing. Xn instead of $\mathrm{Xi}$, def in SDS)

Minor deficits: $58.8 \% \quad$ (Not totally correct R phrases, wrong names headings in SDS)

Table 2. Comparision of Technical Dossier, Chemical Safety Report, and Safety Data Sheet

\begin{tabular}{|c|c|c|c|}
\hline & Technical Dossier & CSR & SDS \\
\hline $\begin{array}{l}\text { Volume for } \\
\text { requirement }\end{array}$ & $>1 \mathrm{t} / \mathrm{a}$ & $>10 \mathrm{t} / \mathrm{a}$ & $\begin{array}{l}\text { For dangerous } \\
\text { substances and } \\
\text { preparations; } \\
\text { PBT and vPvB }\end{array}$ \\
\hline Focus & Substances & $\begin{array}{l}\text { Substances, can } \\
\text { be produced for } \\
\text { preparations }\end{array}$ & $\begin{array}{l}\text { Substances and } \\
\text { preparations }\end{array}$ \\
\hline Context & Art. 10; Annex VI-XI & Art. 14; Annex I+XII & Art. 31; Annex II \\
\hline Content & $\begin{array}{l}\text { Data collection, } \\
C+L \text {, } \\
\text { study summaries, } \\
\text { uses and exposure } \\
\text { information, guidance } \\
\text { on safe use, } \\
\text { test proposals, if } \\
\text { needed }\end{array}$ & $\begin{array}{l}\text { Risk assessment, } \\
\text { information for risk } \\
\text { management, } \\
\text { uses and exposure } \\
\text { information, } \\
\text { C+L }\end{array}$ & $\begin{array}{l}\text { Hazard and risk } \\
\text { information, information } \\
\text { for risk management, } \\
\mathrm{C}+\mathrm{L} \text {, } \\
\text { annex with exposure } \\
\text { scenarios }\end{array}$ \\
\hline Addressees & $\begin{array}{l}\text { Agency, internal } \\
\text { document for } \\
\text { producers or importers }\end{array}$ & $\begin{array}{l}\text { Agency, internal } \\
\text { document for } \\
\text { producers or importers, } \\
\text { customers }\end{array}$ & $\begin{array}{l}\text { Customers, users of the } \\
\text { chemical }\end{array}$ \\
\hline
\end{tabular}

\section{Evaluation - Authorities Assuring Quality of Assessment}

\section{Evaluation - Recital 16}

"The evaluation provisions provide for follow-up to registration, by allowing for checks whether registrations are in compliance with the requirements of this Regulation and if necessary by allowing for generation of more information on the properties of substances. If the Agency in co-operation with the Member States considers that there are grounds for considering that a substance constitutes a risk to health or the environment, the Agency should, after having included them in the Community rolling action plan, relying on the competent authorities of Member States, ensure that these substances are evaluated."

The evaluation of dossiers and substances is an important part of the future work of the Chemicals Agency and the member-state authorities. It could be interpreted as an audit assuring the quality of the assessments. One important task of the authorities will be to screen all registration data for possible candidates for evaluation. They have to decide which dossiers are evaluated. Apart from this direct approach there will also be an element of chance, as some registration dossiers will be randomly picked and evaluated. Two aspects must be distinguished:

- Dossier evaluation

- Substance evaluation

\subsection{Dossier Evaluation}

This step can be regarded as a quality check of selected elements of the registration dossier: A compliance check of registrations will be performed for at least $5 \%$ of the dossiers in each tonnage band. In addition, the technical dossier including the CSR will be checked for completeness, and the conclusions regarding risk management for their reliability. Furthermore, all proposals for additional testing (e.g. for higher tonnages as specified in the Annexes), have to be reviewed by the Chemicals Agency. The aim of the review is to decide

- whether the testing proposals are in compliance with the testing requirements for the respective production/import tonnages according to the Annexes, or

- whether the registrant or downstream user need to perform the proposed or modified testing, and to set a deadline for submission of the requested information.

If several registrants of one substance have to address the same issue, they have to be informed to agree on a joint submission of data or testing. This important aspect should address the items of waived tests, $e$.g. for animal welfare reasons. 


\subsection{Substance Evaluation}

The substance evaluation is the step in $\mathrm{REACH}$ that involves the expertise of the authorities by performing a risk assessment themselves. Substance evaluation should be considered for substances of high concern or if risks are not adequately controlled. The challenging task for the authorities will be to propose criteria to identify candidates for evaluation. Promising candidates for evaluation could be substances with properties such as persistence, bioaccumulation potential or high toxicity. Additional criteria for considering substances for further evaluation might be wide and dispersive uses or uses in consumer products. To standardise the approach, a set of criteria to screen the registration information have to be developed. As an example, criteria to identify possible PBT- or vPvB-substances need to be agreed on to start the process of consideration for inclusion into Annex XIV (see also Section 8).

If the risk assessment performed by the authorities identifies a need for further information, this may be forwarded to the Chemicals Agency to request further implementation legally. Authorities could ask for additional information to finalise certain aspects of the risk assessment. Another possibility for requesting additional information could be the intention to compile an Annex XV dossier. With this type of dossier, to be prepared by the authorities, the need for risk management on Community level has to be justified.

For substance evaluation, an EU-wide Community rolling plan will be established. The plan will be prepared by the Agency with input from the Member States and updated regularly. It is scheduled to evaluate 50-100 substances annually starting in the 4th year after entry into force of REACH.

\subsection{Annex XV Dossier - Transfer- ring Evaluation Results to Risk \\ Management}

The Annex XV dossier will introduce the following aspects into legislation:

- Harmonisation of the classification and labelling of CMR-substances (carcinogenic, mutagenic, or toxic for reproduction) and inclusion into Annex XIV;

- Proposal to enter substances into Annex $\mathrm{XIV}$ as a prerequisite for authorisation, i.e. $\mathrm{PBT}$, $\mathrm{vPvB}$, or substances of equivalent concern;

- Proposal of the need for Communitywide measures for risk management (e.g. restrictions).

In addition to classification and labelling with regard to CMR properties, an Annex XV dossier could also be reasonable to harmonise classification and labelling of other properties. This might be the case if conflicting proposals were submitted to the agency, or if the proposal of a registrant is misleading.
Following the submission of an Annex XV-dossier by a member state and several formal steps, the dossier is forwarded to a voting committee to decide on the proposed measure.

\section{Authorisation - Authorities Proposing Additional Management Needs}

According to Article 54, the production and use of chemicals of very high concern is subject to authorisation. The main intention of this approach is to promote substitution of hazardous chemicals with those with less dangerous properties or at least to guarantee an adequate control of the risks from chemicals towards humans and the environment over their whole life cycle.

\section{Authorisation - Recital 63}

"To ensure a sufficiently high level of protection for human health, including having regard to relevant human population groups and possibly to certain vulnerable sub-populations, and the environment, substances of very high concern should, in accordance with the precautionary principle, be subject to careful attention. Authorisation should be granted where natural or legal persons applying for an authorization demonstrate to the granting authority that the risks to human health and the environment arising from the use of the substance are adequately controlled. Otherwise, uses may still be authorized if it can be shown that the socio-economic benefits from the use of the substance outweigh the risks connected with its use and there are no suitable alternative substances or technologies that are economically and technically viable. Taking into account the good functioning of the internal market it is appropriate that the Commission should be the granting authority."

Once a member state's competent authority identifies a substance as a candidate for authorisation, e.g. during the substance evaluation step, the member state can suggest inclusion into Annex XIV. This could be the case for CMR substances (carcinogen, mutagen, toxic for reproduction) and also for substances with PBT- or vPvB properties or of equivalent concern.

If the authority is convinced that a substance is of very high concern and risk management measures already implemented are not appropriate to control the risks adequately, the authority initiates the process by preparing an Annex XV dossier. With this dossier, the authority must communicate the outcome of the risk assessment to the agency and stakeholders. Preparing an Annex XV dossier should only be considered if local measures are not sufficient, and hence additional action at community level is required. To substantiate the argumentation for introducing common management measures, authorities might include a comparative risk assessment of possible alternatives and their risks. Showing that alternatives are available and pose minor risks improves the decision making. Additionally stakeholders can submit a costbenefit analysis to backup the necessity of the substance. If a substance cannot be adequately controlled but substitution is economically not reasonable it stays on the market.

Following a prioritisation procedure and a decision involving a member states committee, the substance may become subject to authorisation by being included into Annex XIV of the Regulation. Once a substance is included in Annex XIV, uses have to be authorised.

A second important intention of the authorisation is to promote the use of substitutes or alternatives with minor risks. For a successful authorisation, producers, importers or users must demonstrate that no suitable alternatives are available. In addition, a socio-economic analysis must be submitted with the request for authorisation. If the argumentation is convincing, and no alternatives are available the Chemicals Agency can authorise the respective use.

In a reversal of the REACH principle of shifting the responsibility for safe substances and processes towards producers and importers, the burden of proof is with the authority: With the exception of requesting authorisation, this legal element of REACH is under the responsibility of the authorities. The challenging task of the authorities will be to demonstrate the need for an inclusion into Annex XIV. This is a crucial weakening of the ability of REACH to ensure a sound management of risks and promote safe chemicals, because decisions can be delayed by encouraging extensive discussions about testing procedures and continuing the marketing and use. This was also identified as a crucial deficit of the existing substances procedure which was expected to be terminated by REACH.

\section{Legal Risk Management Under REACH}

One important intention of REACH is to close the extensive information gaps on existing substances and rely as much on the internal forces and capacities of the market as reasonable. Therefore hazard and risk information is reviewed and streamlined by the Chemicals Agency if several assessments were submitted. The Agency will be responsible for a standardized data and information management. National authorities inform the 
public and pass on relevant new facts about potential risks to the Agency.

It is not clear how the implementation process of risk management measures which are ruled by the different economic actors will be monitored and controlled. The practical outcome of risk management under REACH is quite difficult to model since the multitude of substance stewards can come to a great variability of decisions. Effects in the environment might occur at different endpoints with relevant delay and the difficulties in defining sources of certain releases will not decrease under REACH. The development of a systematic controlling of the implementation process and the results is the responsibility of the Member States. They could use existing reporting and monitoring tasks such as the Pollution Release Toxic Register (PRTR) [15] or the monitoring obligations related to the river basin management plans (Annex VIII of the EU Water Framework Directive - WFD) [16]. But neither REACH nor the other sectoral legislation refers explicitly to each other.

\section{Monitoring the REACH Output and Outcome}

The 'dispersion of toxic substances' is one of ten environmental policy fields that are monitored through a set of highly aggregated indicators [17] by Eurostat and the European Environmental Agency (EEA). Parallel with the preparation for the REACH process Eurostat started to develop an indicator set according to the Driving forces, Pressure State Impact Response (DPSIR) scheme. In $2001 \mathrm{Eu}-$ rostat published an Environmental Pressure Indicator (EPI) and in 2005 followed this with a chemical risk index (CRI) as well as running a project to define a baseline of the REACH system, which focuses on the increase in data availability and quality, using an in depth analysis of selected reference substances. The EEA is responsible for impact indicators. Currently the indicators used for the impacts of chemicals are a) mother milk and b) a marine biomarker. Data sources to be used for the latter, however, are still under discussion.

\subsection{Classification and Labelling (Directives EC 67/548, EC/1999/45)}

Dangerous properties of substances and preparations have to be determined, classified and communicated to professional users with labels and Safety Data Sheets. This information focuses on a non-quantified characterisation of substance properties (hazard assessment). A multitude of regulations and technical rules refer to the classification and justify specific legal risk management measures [18]. The Chemicals Agency will pro- vide an inventory of substance classification and labelling. The relevance of this instrument will even increase when the Globally Harmonized System of classification and labelling (GHS) will enter into force.

\subsection{Restrictions of Marketing and Use (Directive EC 76/769) [19]}

Restriction of dangerous uses and authorisation of substances with systemic risk potential are the main legal instruments at EU level to control risks directly. Annex XIV will consist of a list of substances for authorisation, and Annex XVII replaces EC 76/769 with regard to restrictions of dangerous uses. Both annexes will be amended continuously according to technical and scientific progress as well as to new substance information.

The necessity of legal measures has to be evaluated extensively. Risks need to be balanced against social and economic benefits. Proposals for restrictions are managed by the EU Commission taking into account the information and judgement of interested stakeholders including economic and scientific arguments.

REACH will expand the scope of restrictions and enable certain conditions of use to be defined as well as the prohibition of certain uses by introducing them into Annex XVII. This should lead to more harmonized emission limit values for the whole EU.

\subsection{Missing Links between REACH and Other Environmental Legislation}

REACH broadens the possible scope of risk management decisively, but thus overlaps with other sectoral legislation and possibly causes new frictions: In future the whole life cycle of a substance will be subject to risk assessment and it will be necessary to define and communicate adequate control for each step. Many particular aspects of production, use and disposal are already legally dealt with.

Clarification is required on how the new knowledge on substances and risk thresholds will influence other fields of health protection and environmental legislation. A reference to sectoral legislation concerning risk management is made only in the authorisation section of the REACH draft. In this context it is presumed that environmental quality targets which were derived under Water legislation (WFD) [16] or under the IPPC Directive [20] were derived as a threshold of 'adequate control' for substances of very high concern. This reference puts the cart before the horse: An identification of chemicals that pose a systemic risk potential is executed only in the REACH system.

References concerning the scope of $\mathrm{REACH}$ and risk assessment are more extensively described. Applicants may include 'a justification for not considering risks to human health and the environment' arising either from emissions of a substance from an installation for which a permit was granted in accordance with the IPPC Directive [20] or discharges of a substance from a point source as referred to in the WFD [16]. However, this clause circumvents the precautionary target of authorisation: The permit for an installation is not able to address a substance-related risk adequately, since it is based on the best available technical standard and not on a quantified single substance risk assessment. This exclusion from the scope of authorisation was therefore criticized heavily by the Competent Authorities. The actual phrase combines both approaches and leaves the burden of proof to the applicant.

\section{Example: PBT Substances}

PBT is the abbreviation for persistent, bioaccumulative and toxic, $v P v B$ stands for very persistent and very bioaccumulative. An important intention of REACH is to assure an adequate technical control of the risks of substances with PBT or vPvB properties or preferably to ensure substitution of such substances as far as possible.

\subsection{Role of the Notifier of PBT Substances}

According to Annex I, producers and importers are obliged to perform an assessment of PBT/vPvB properties as an essential part of the CSR. Hence, for substances produced or imported at levels of more than $10 \mathrm{t} / \mathrm{a}$, a PBT-assessment is required. For substances identified as PBT or $\mathrm{vPvB}$, an emission characterisation also must be included in the CSR as the second step. For substances which are considered as potential PBT or $v \mathrm{PvB}$, a proposal for further testing must be submitted with the CSR. The intention is to prove whether the definitive criteria of Annex XIII (Table 3) are fulfilled or not.

If a substance is considered as PBT or vPvB in the CSR, the respective producer or importer must identify and apply appropriate measures to adequately control the risks. Since an adequate control of the risks of a PBT or vPvB substance is hardly possible after its release into the environment, zero emission is the requirement for identified PBT/vPvB substances for precautionary reasons (Table 3).

\subsection{Role of the Authorities Handling PBT Substances}

PBT and $v P v B$ substances are subject to authorisation and hence are of high priority for inclusion into Annex XIV. For a substance identified as PBT or vPvB by fulfilling the criteria of Annex XIII, the authorities can propose an inclusion into Annex XIV. However, this is only required with high priority if the risks are not adequately controlled and Community-wide action is appropriate to manage the risk. 
Table 3. Criteria for identifying PBT- und vPvB Substances according to Annex XIII

$\begin{array}{lll}\text { Criterion } & \text { PBT } & \text { vPvB } \\ \text { Persistence } & \text { Half-life } & \text { Half-life } \\ & - \text { salt water: }>60 \text { days } & - \text { water: }>60 \text { days } \\ & - \text { fresh water: }>40 \text { days } & \\ & - \text { marine sediments: }>180 \text { days } & \text { - sediment: }>180 \text { days } \\ & - \text { limnic sediments: }>120 \text { days } & \\ & - \text { soil: }>120 \text { days } & - \text { soil: }>180 \text { days } \\ \text { Bioaccumulation } & \text { BCF }>2000 & \text { BCF }>5000 \\ \text { Toxicity } & - \text { NOEC (aquatic organisms) }<0.01 \mathrm{mg} / \mathrm{I} & \\ & - \text { CMR (canzerogenic, mutagenic, toxic } & \\ & \text { for reproduction) }(T, R \text { 48, } \mathrm{Xn}) & \end{array}$

An important task of the authorities is to identify potential PBT and $\mathrm{vPvB}$ candidates among the registered substances. There are at least five possibilities:

a) A substance is already identified as PBT or $v \mathrm{PvB}$ in the CSR, and the proposed risk management measures are adequate to control the risk.

b) A substance is already identified as PBT or $\mathrm{vPvB}$ in the CSR, but the proposed risk management measures are not adequate to control the risk.

c) A substance is identified as possible PBT or $\mathrm{vPvB}$ in the CSR, and a testing proposal is included.

d) The substance is identified as possible PBT or $\mathrm{vPvB}$ in the CSR, and no testing proposal is included, e.g. since testing is not technically feasible.

e) The substance is not identified as PBT or vPvB candidate although it could be one. This is true for all PBT or vPvB-candidates produced or imported with $<10 \mathrm{t} / \mathrm{a}$, because no CSR is required. This may also be the case if the conclusion drawn in the CSR is wrong.

For option a, no priority action is required. The obligations are fulfilled and the risk is adequately controlled. For option b, an inclusion into Annex XIV can be proposed without delay. For the other options, authorities have to evaluate the substance first. In most of the cases, further information is required to allow a conclusion whether the criteria are fulfilled or not. For example, the information requirements for substances registered in volumes between 10 and 100 t/a might only anticipate possible PBT properties. An estimation of reliable half-lives is not possible based on the data to be submitted with the CSR as data set with regard to Annex VIII (10-100 t/a). In addition, only a prediction of the bioconcentration potential is possible for substances produced or imported below 100 t/a due to missing measured data. Since Annex XIII predominantly reflects on measured data, for many possible PBT or $v \mathrm{PvB}$ candidates further experimental testing would be required before a definitive decision about the PBT status is possible.
Again, the main principle of $\mathrm{REACH}$, giving the burden of proof to the notifiers, is being contravened. For an inclusion into Annex XIV authorities must demonstrate that a substance is a PBT or vPvB substance. For some of the most likely substances this might be difficult to achieve due to difficulties in having appropriate tests available. Hence, many substances which might be regarded as $\mathrm{PBT}$ or $\mathrm{vPvB}$, e.g. due to findings in top predators in remote areas and observed toxic effects, have to be considered as substances of equivalent concern in spite of being persistent, bioaccumulative and toxic in nature.

To substantiate the precautionary principle for PBT and $\mathrm{vPvB}$ substances, it is suggested that the following procedure be established: For substances which need to be considered as potential $\mathrm{PBT}$ or $\mathrm{vPvB}$ by fulfilling PBT screening criteria, an inclusion into Annex XIV should be considered if the non-PBT or non-vPvB status cannot be demonstrated by the registrant within a given time-frame.

\section{A Major Shortcoming of REACH: Chemicals in Articles}

REACH focuses on the EU domestic market. Risks caused by substances in products should be generally excluded by the manufacturers' recommendations for a safe use that are passed on through the supply chain using the technical dossier. REACH does not, however, include comparable mechanisms for unknown and unintended releases caused by dangerous substances in import products. Nevertheless imported products might contribute considerably to the risks to human health and the environment.

Article 7 of REACH describes under which conditions producers and importers of articles are required to register or notify substances contained therein. Requirements are proposed for registration of substances that exceed quantities totalling over $1 \mathrm{t} / \mathrm{a}$ per importer/producer, and for substances intended to be released under normal or foreseeable conditions of use. Any producer or importer of articles must notify articles containing a
CMR, PBT, vPvB or substance of equivalent concern in concentrations above $0.1 \%$ and $1 \mathrm{t} / \mathrm{a}$.

The identification of dangerous substances in articles is an unsolved problem causing concerns for authorities and industry, especially those involved in consumer markets. The responsibility for potential risks caused by this pathway has not been clarified. For example, although the German chemical industry shut down the production of brominated flame retardants (BDE) in 1986 voluntarily as part of their responsible care commitments, recent concentrations of BDE in sewage sludge are 13 times higher as reported for Germany in 1992 due to the increasing use of flame retardant polymer materials [21].

In addition, risk arising from unintended releases of substances from articles will not be covered by REACH (Article 7), though the release is a known fact. However for substances of high concern (i.e. CMR) in articles a notification is required. Dangerous substances which do not fall under this provision may be released unintentionally in relevant amounts. This includes substances protecting articles during transport and storage (e.g. corrosion protection substances on bolts) or substances in closed articles which might be released after or during their use.

\subsection{Definition of 'Article' and 'Article with Intended Release'}

In the draft regulation, an article is defined as "an object which during production is given a specific shape, surface or design which determines its function to a greater degree than does its chemical composition". However, discussions around practical examples have found that this definition is ambiguous and does not always allow a clear distinction between an 'article' and a 'preparation contained in a container'. In addition 'intended release' is not defined. To be able to conform to REACH it is mandatory that all stakeholders come to the same understanding of what exactly an article is.

\subsection{Preconditions to Enable Authorities to Control Substances in Articles}

According to REACH, substances in articles are defined as uses. However, for imported products the integration of risk information and management recommendations as well as the allocation of the product into the information exchange within the supply chain is not defined in a satisfactory way.

Although the responsibility for the safe production and handling of chemicals will lie with industry, national authorities will have to enforce and control the implementation of REACH. In order to guarantee an equal treatment of substances marketed in the EU and substances in articles that are imported, several information requirements have to be 
met. At the most basic level it needs to be clearly distinguished between

- substances in articles with intended release;

- substances in articles to be included in Annex XIV (substances subject to authorisation).

\subsection{Points of Conflict and Approaches for Their Solution}

In the context of substance stewardship the question for economic actors arises to which degree an importer will have to know the identity of substances contained in articles, how exact documentation will have to be and how it would be feasible to guarantee safe products. This is a conflict similar to the one dealing with substances in preparations, which is also unsolved and debated controversially. It is questionable if REACH will be able to integrate this problem adequately. It might be more reasonable to look for other instruments that focus on products and establish legal links that promote a better cooperation.

Nowadays, lists of substances are not unusual in supply contracts. Contracts may contain declaration duties or bans of certain substances, to secure certain product qualities (including the aim to avoid possible scandals). Product inventories run by authorities might be a useful amendment to the substance inventory at the Chemicals Agency. The Scandinavian internet database 'Substances in Preparations in Nordic Countries - SPIN' [22] and the product register of Switzerland [23] are well-established approaches and might serve as an example for a cooperative system of information exchange on articles.

Legal links and horizontal cooperation should be facilitated, i.e. existing control mechanisms for products covered by other legislative provisions (e.g. in the Cosmetics Directive) could be used to include possible routines of control of REACH requirements.

\subsection{Conclusion}

The current draft of REACH does not implement feasible provisions to integrate substances in articles into the processes of information exchange and risk management recommendations. Possible technical requirements are still under discussion in the Reach implementation process. REACH could give an incentive to importers of substances to include information on dangerous substances in their contracts and in existing quality management systems, e.g.:

- Producers/importers of articles who have already implemented management systems such as the Eco-Management and Audit Scheme (EMAS) could incorporate REACH conformity as a quality criterion accepted by the authorities - with clear indications of how conformity will be secured and documented.
- Importers (e.g. SMEs) without a management system may follow a kind of 'good importing practice for articles'. This might include following workflows, describing whether registration/notification is required, and supporting documents $e . g$. letters from suppliers, certificates or results of analysis.

For authorities, controlling compliance with REACH is difficult for substances in articles, because compliance can not be checked easily on the article itself or by analysing the article. During the RIP 3.8 project different proposals for generating and transferring the necessary information have been suggested. Binding rules for accompanying documents and a centralised collection of amounts imported per year and per actor have been discussed as difficult to be performed and legally questionable [24].

Although national measures are needed, a standardised procedure would have been much preferable to ensure that no internal barriers to trade are created within the EU. Thus an important factor for the successful implementation of $\mathrm{REACH}$ requirements will be cooperation between authorities at EU level and the Member States as well as a better horizontal exchange of information. Thus a proactive attitude towards new roles and new tasks under REACH should concern officials just the same as economic actors.

Received: August 14, 2006

[1] Council of the European Union, Common position adopted by the Council on 27 June 2006 (REACH); (7524/8/06) Luxembourg, 2006; http://register.consilium.europa.eu/ pdf/en/06/st07/st07524-re08.en06.pdf.

[2] Council of the European Union, Common Position adopted by the Council on 27 June 2006 (REACH); (7525/3/06) Luxembourg, 2006; http://register.consilium.europa.eu/ pdf/en/06/st07/st07525-re03.en06.pdf.

[3] M. Führ, K. Bizer, 'REACh as a paradigm shift in chemical policy - responsive regulation and behavioural models', J. Cleaner Prod. 2006, 14, in press - available online.

[4] United Nations; United Nations Conference on Environment \& Development Rio de Janerio, Brazil, 3 to 14 June 1992; AGENDA 21, http://www.un.org/esa/sustdev/documents/agenda21/english/agenda21chapter19.

[5] Council Directive 67/548/EEC of 27 June 1967.

[6] Council Regulation (EEC) No 793/93 of 23 March 1993.

[7] Directive 1999/45/EC of the European Parliament and of the Council of 31 May 1999.

[8] European Commission, Technical Guidance Document on Risk Assessment; Ispra 2003, http://ecb.jrc.it/tgdoc/.

[9] C.W.M. Bodar, F. Berthault, J.H.M. de Bruijn, C.J. van Leeuwen, M.E.J. Pronk, T.G. Vermeire, 'Evaluation of EU Risk
Assessments Existing Chemicals (EC Regulation 793/93)', Chemosphere 2003, 53, 1039-1047.

[10] The progress of REACH IT is documented at the website of the ECB: http://ecb.jrc. it/REACH-IT-INFORMATICS/.

[11] European Parliament legislative resolution on REACH [P6_TA(2005)0434], 2005.

[12] ECB Website with information and reports from the REACH Implementation Projects: http://ecb.jrc.it/REACH/RIP_PROJECTS/.

[13] B. Franke, H. Fehrenbach, 'Mechanisms and Requirements for a Quality Management System under the REACH Regulation', Umweltbundesamt, Study Report No. 00081116, Berlin, 2005.

[14] European Classification and Labelling Inspections of Preparations, including Safety Data Sheets, 2004, http://www.cleeneu.net/projects/ECLIPS_Final_report.pdf.

[15] Regulation (EC) No 166/2006 of the European Parlament and of the Council of 18 January 2006 concerning the establishment of a European Pollutant Release and Transfer Register and amending Council Directives 91/689/EEC and 96/61/EC.

[16] Directive 2000/60/EC of the European Parliament and of the Council establishing a framework for the Community action in the field of water policy.

[17] EUROSTAT, ENV/045/07, 2005, p. 24.

[18] European Chemicals Bureau, Downstream Consequences on other Community Legislation arising from the Classification and Labelling of Dangerous Substances under Directive 67/548/EEC ECBI/31/99 Rev. 5; Ispra, 2003, http://ecb.jrc.it/DOCUMENTS/Classification-Labelling/3199r5 ECB_Downstream_legislation.doc.

[19] Council Directive 76/769/EEC of 27 July 1976.

[20] 96/61/EC Directive on the Integrated Pollution Prevention and Control.

[21] W. Knoth, W. Mann, R. Meyer, J. Nebhuth, Organohalogen Compounds 2004, 66, 3749-3754.

[22] SPIN, http://www.spin2000.net/spin.html.

[23] Schweizer Produktregister, http://www. parchem.bag.admin.ch/webinfo/global/.

[24] Reach Implementation Project 3.8, Draft Technical Guidance Document on requirements for substances in articles (Service Contract No. CCR.IHCP.C430598. XO) 2006. 